\title{
Facts, Opinions, and Media Spectacle: Exploring Representations of Business News on the Internet
}

\author{
Sabine Tan \\ Multimodal Analysis Lab \\ Interactive \& Digital Media Institute (IDMI) \\ National University of Singapore
}

\begin{abstract}
In the twenty-first century, the field of business and finance has become a media spectacle. Not only have advances in technology changed the ways in which audiences engage with business information, the pervasiveness of internet and cable television networks has led to the emergence of new hybrid forms of business news discourse, blending verbiage, images, graphics, audio and video clips. Combining discourse analysis, social semiotic theory, and other interdisciplinary approaches, this article explores the multiple ways in which business news are mediated on the internet by continuous 24-hour business news networks such as Bloomberg, CNBC, FOXBusiness, and Reuters. In particular, this article is concerned with how events are contextualized, that is, how identities and social relationships are constructed and represented within and across different modes, media, and networks. The analysis focuses on what is foregrounded or backgrounded, what is thematized or unthematized in each mode and medium, and what process types and categories are drawn upon to represent events, social actors and social (inter)actions. In this context, special interest is being paid to the semiotic shifts or transformations (and ensuing re-contextualizations) that multimodal representations undergo across modes, media, and news networks.
\end{abstract}

KEY WORDS: business news discourse, cable news networks, cable network television, recontextualization, discourse analysis, internet news, multimodal representations, on-line business news, social actor, social interaction, social semiotic theory 


\section{Introduction}

The news is probably one of the most widely researched discourse genres in a variety of disciplines, in particular from text-linguistic perspectives. Business news discourse, specifically the continuous twenty-four-hour network version mediated through the internet has remained, however, an under-theorized area of academic enquiry. Moreover, many traditional methods and theoretical frameworks for the analysis of news discourse have tended to work within the confines of the printed page.

In the twenty-first century, the field of business and finance has become a media spectacle. As Clark et al. (2004) observe, business and financial news are

\footnotetext{
... a never-ending series of daily stories, issuing from the pink pages of respectable broadsheet newspapers and other print media and increasingly dominated by the cacophony of voices, images and events broadcast by television and on-line real-time data services. Finance has become a media event, with its breathless reporters and star anchorpersons ... This fact of financial life could be treated as ephemeral and of minor significance (compared to the 'real' facts of economic principles). But financial institutions take it very seriously indeed. (Clark et al., 2004: 289)
}

Nonetheless, in the digital age, the way business news is mediated has become radically different from the structured, predominantly text-based, representations that one finds in respectable broadsheets. Not only have advances in technology altered the ways in which audiences engage with and receive business information, the emergence of network television and the internet has also changed the ways in which news networks present events, social actors, and social (inter)actions to their audiences. In an era in which business and finance news has become increasingly complex and difficult to represent, we know - as yet very little about the relationship of reporting financial and business data in the medium of print (or the medium of hypertext, for that matter), and financial reporting in the medium of television. In addition, the research community is still largely ignorant "about the design and structure of financial reporting in these rather different environments just as we know very little in fact about the significance of historically derived codes of practice in sustaining the divide between reporting information and making opinions about the significance or otherwise of that information" (Clark et al., 2004: 305) - fundamental issues which this article endeavours to address. 
This article will show - on the basis of a pilot case study - that the 'ideological' reading or viewing positions that are constructed by business news networks involving new media are fluid and complex. As Montgomery (2007:20) aptly notes "such complexities pose challenges to any descriptive schema and it is difficult to meet the demands of the task without resorting to the insights of more than one discipline or research tradition”. In order to obtain a more holistic view of the complex ways business news are mediated on the internet and television, this paper this paper thus proposes to adopt an integrative, multidisciplinary approach combining discourse analysis, social semiotic theory, and other interdisciplinary perspectives.

\section{The Case Study}

The article presents the findings of a preliminary, exploratory case study of events related to the Bear Stearns fiasco in connection with the subprime mortgage crisis in the United States, as reported by Bloomberg, CNBC, FOXBusiness, and Reuters, in the space of 24 hours on 19 and 20 June 2008 respectively. The preliminary case study is part of the author's $\mathrm{PhD}$ research, which focuses on the multimodal portrayal of business news as mediated on the internet and television by continuous 24-hour business news networks. The author's research is part of the Events in the World ${ }^{1}$ project at the National University of Singapore. It is concerned with describing the multimodal portrayal of key events in the world in print media, television and the internet by developing and using prototype software for the multimodal analysis of images, video texts, interactive digital sites and 3-D reality.

The pilot case study aims to address the question of how business news events are contextualized on the internet. It explores the various ways how identities and social relationships are constructed and represented within and across different modes, media, and networks. The qualitative analysis focuses on what is foregrounded or backgrounded, what is thematized or unthematized, and what process types and categories are drawn upon to represent events, social actors and social (inter)actions.

The paper begins by briefly outlining the presentational structure potential of hypermediated business news in Section 2 to provide an overview of the complexities of online representations. Section 3 summarizes the underlying theoretical perspectives and 
conceptual models that motivate the research. Section 4 presents the analysis of the case study. Section 4.1 offers insight into representations of social actors that feature as the subject in the verbiage and imagery of a hypermediated news event. Section 4.2 discusses the types of social and personal identity that are set up for newsmakers and newsworkers through social interactive and discursive processes in the video clips of televised broadcasts, while Section 4.3 looks at the positions that are constructed for audiences, and the possible ideological implications that may be encoded in news discourse.

\section{The Presentational Structure Potential of Hypermediated Business News}

Online business news discourse is a complex medium of communication that allows more intertextual relationships to be established between texts and discourses than traditional forms of news media, such as print and television. In traditional media, important content is generally subordinated to the relevance structure of the news, such as hierarchical organization, schematic structure, and corresponding layout (e.g. see van Dijk 1988a:84). Hypermediated business news discourse, in contrast, routinely deploys dynamic, interactive blends of multimedia displays, which can be arranged across several webpages. The result is a fragmented assemblage of macro-event clusters consisting of multiple, and often reduplicated, representations of a single event in the form of verbiage, images, graphic displays, digitized photographs, and embedded audio and video clips (see Figure 2.1 a-b for further elucidation). For instance, in the space of 24 hours, the 'Bear Stearns' event was featured on the networks' webpages

(a) in the homepage headline and/or 'newsbite'2 (Figure 2.1a-b, marked 'A');

(b) in the headlines and/or lead paragraphs on ancillary pages to the homepage, such as the 'Breaking News' page on Bloomberg, and separate sections of the 'Business \& Finance' pages on Reuters (marked 'B');

(c) in the main event or story page (marked ' $\mathrm{C}$ '), inclusive of embedded photographic images (marked ' $E$ ', shaded grey) and/or embedded video clips (marked ' $F$ ', shaded grey);

(d) in the main audio/video page in the form of a thumbnail image, headline, and summary-lead (marked 'D')

(e) in the headline and summary-lead on the video pop-up sub-page (marked 'E')

(f) in the photo captions on the photo pop-up sub-page (marked ' $F$ '). 


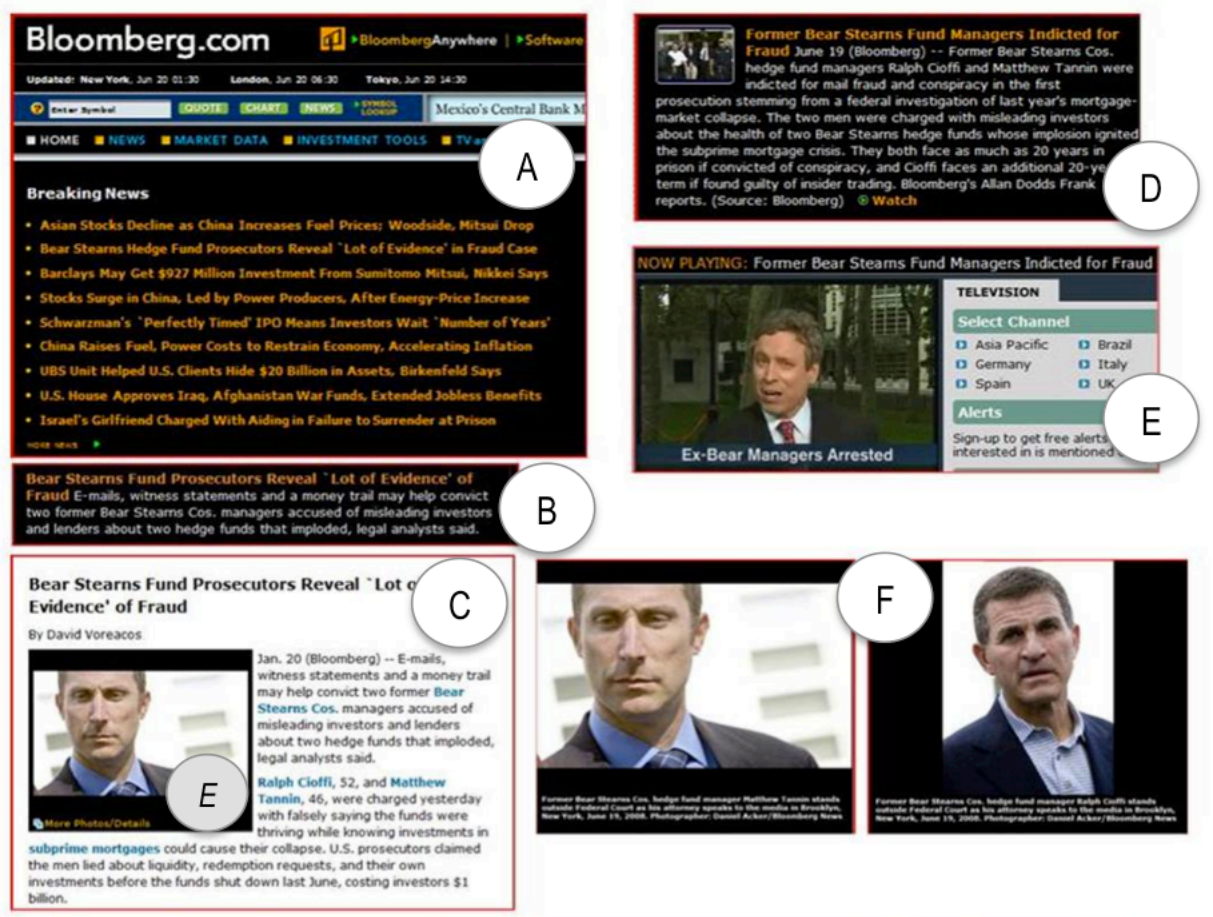

Multimodal Representations of the Event on Bloomberg.com

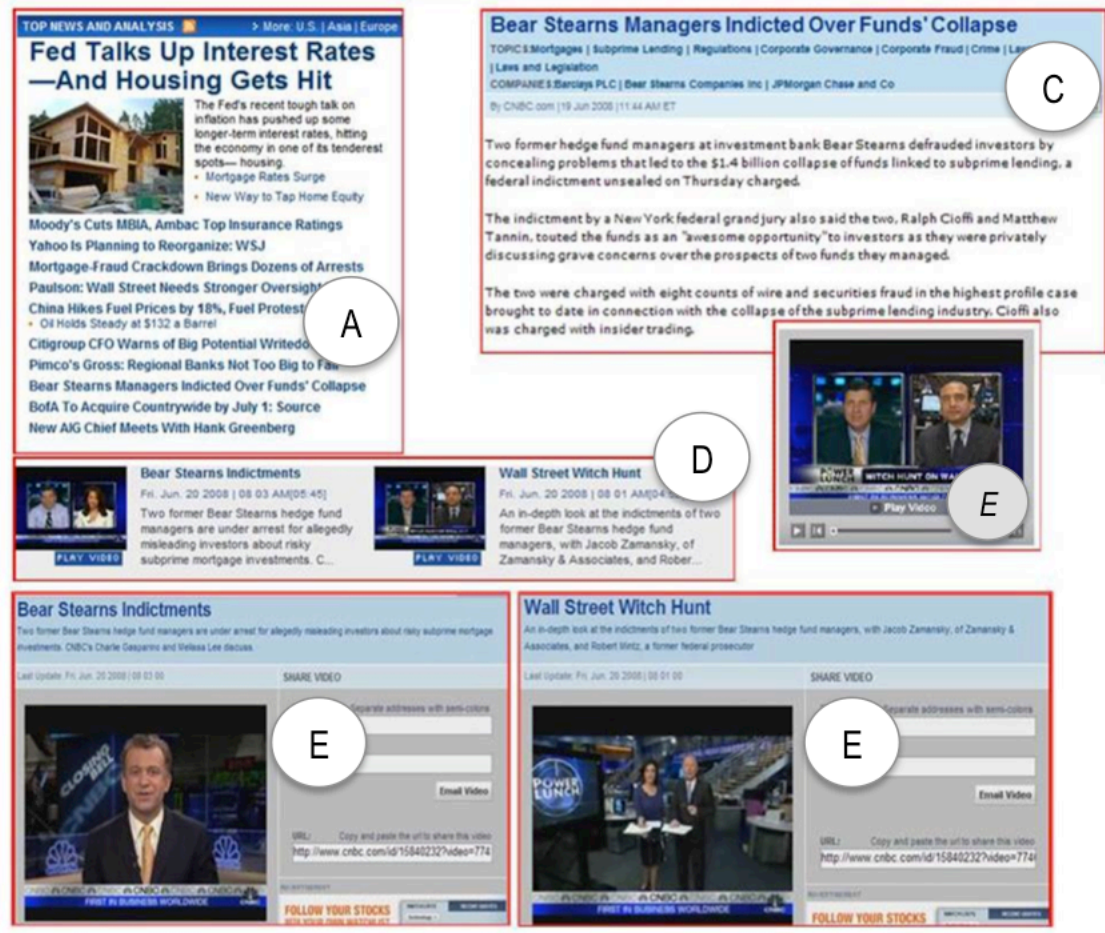

Multimodal Representations of the Event on CNBC.com

FIGURE 2.1a Multimodal Representations of the Event on Bloomberg.com and CNBC.com 


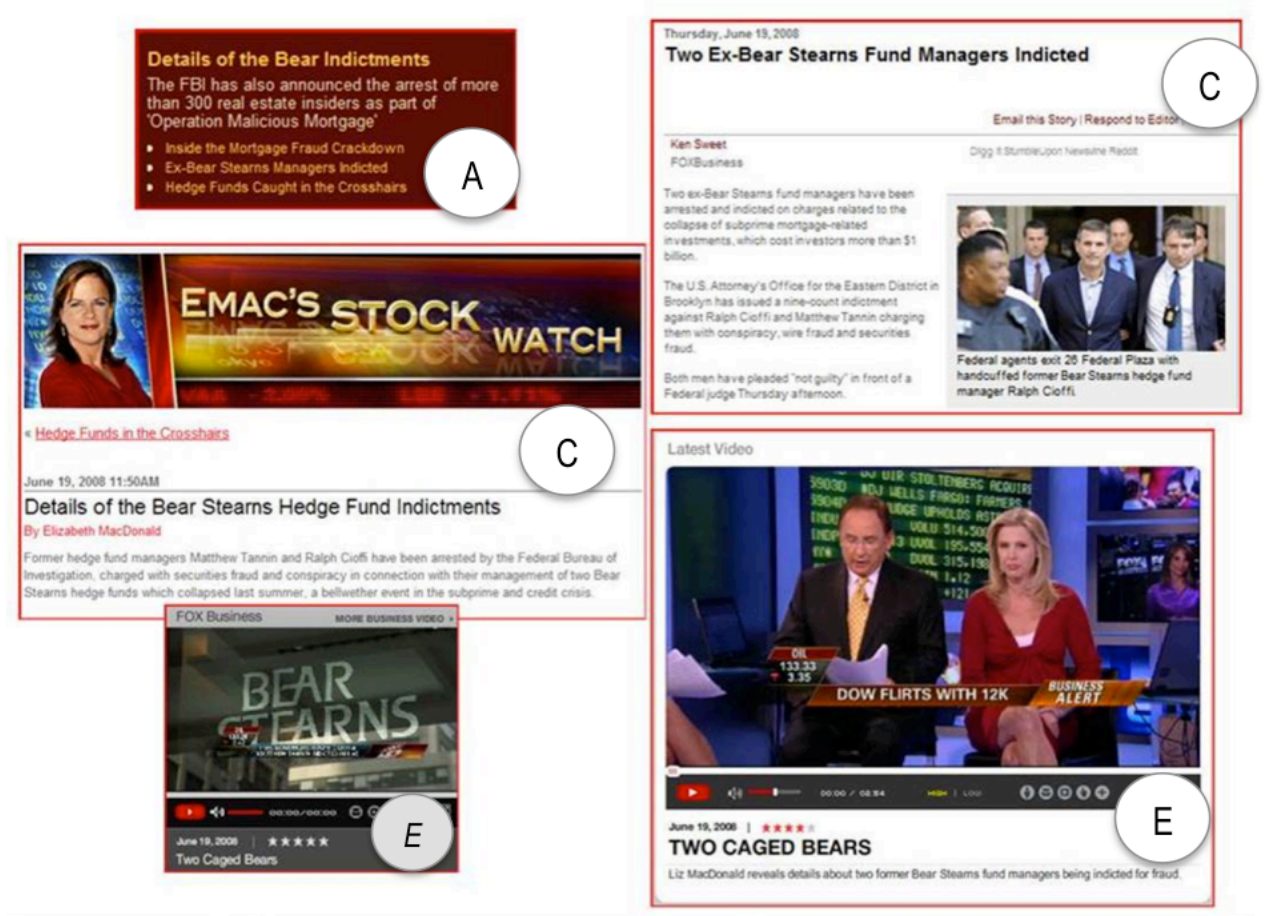

Multimodal Representations of the Event on FOXBusiness.com

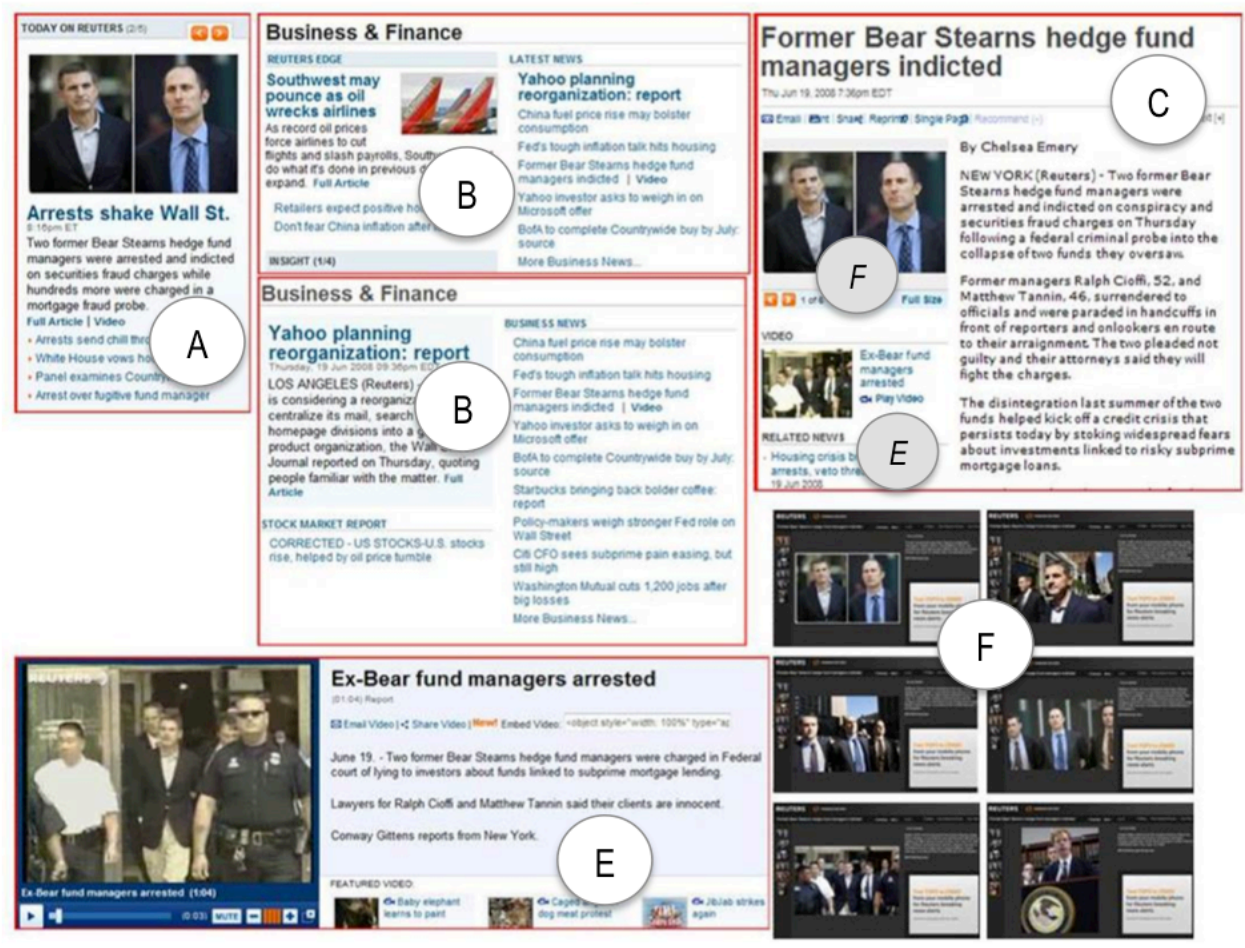

Multimodal Representations of the Event on Reuters.com

FIGURE 2.1b Multimodal Representations of the Event on FOXBusiness.com and Reuters.com 
MACRO-EVENT CLUSTERS

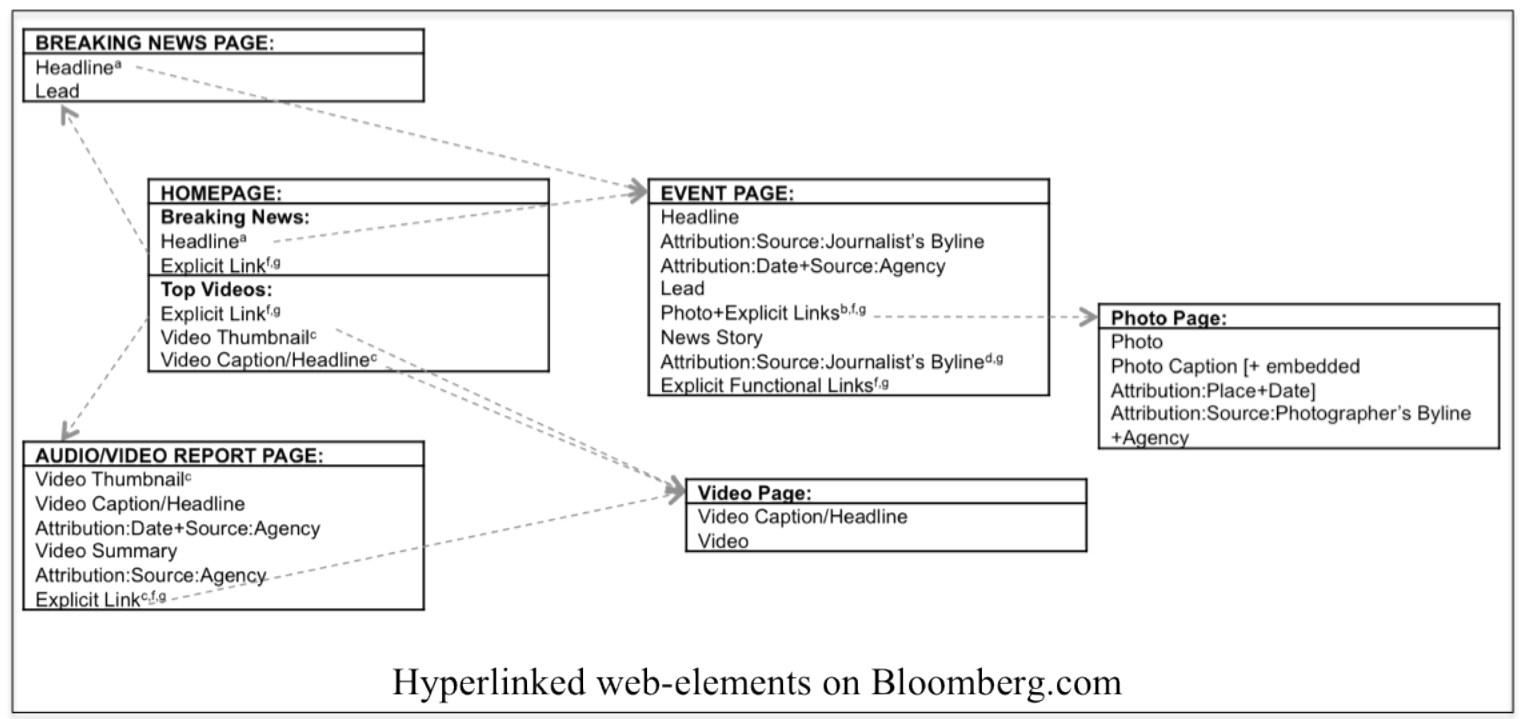

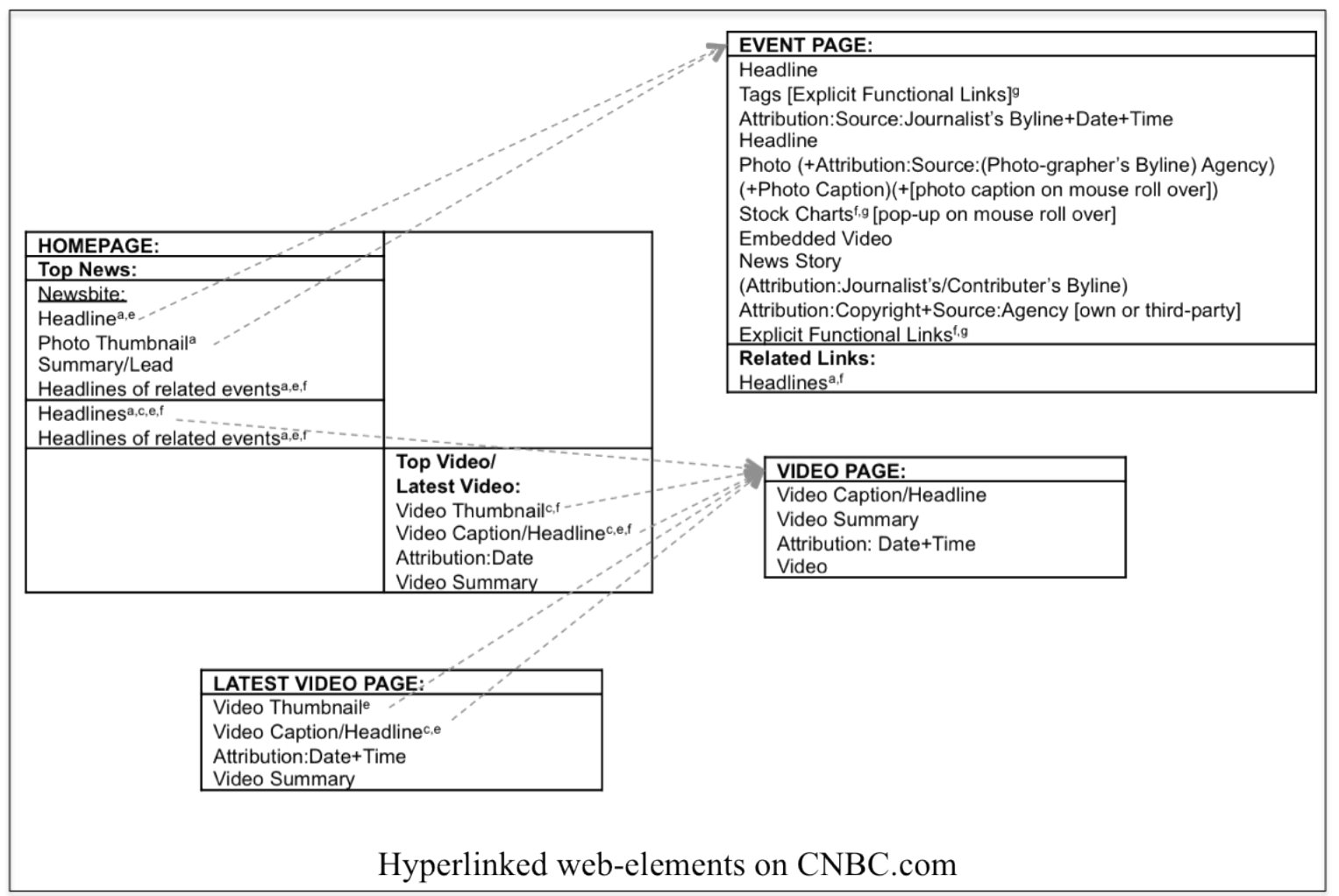

FIGURE 2.2a Hyperlinked web-elements on Bloomberg.com and CNBC.com 


\section{MACRO-EVENT CLUSTERS}

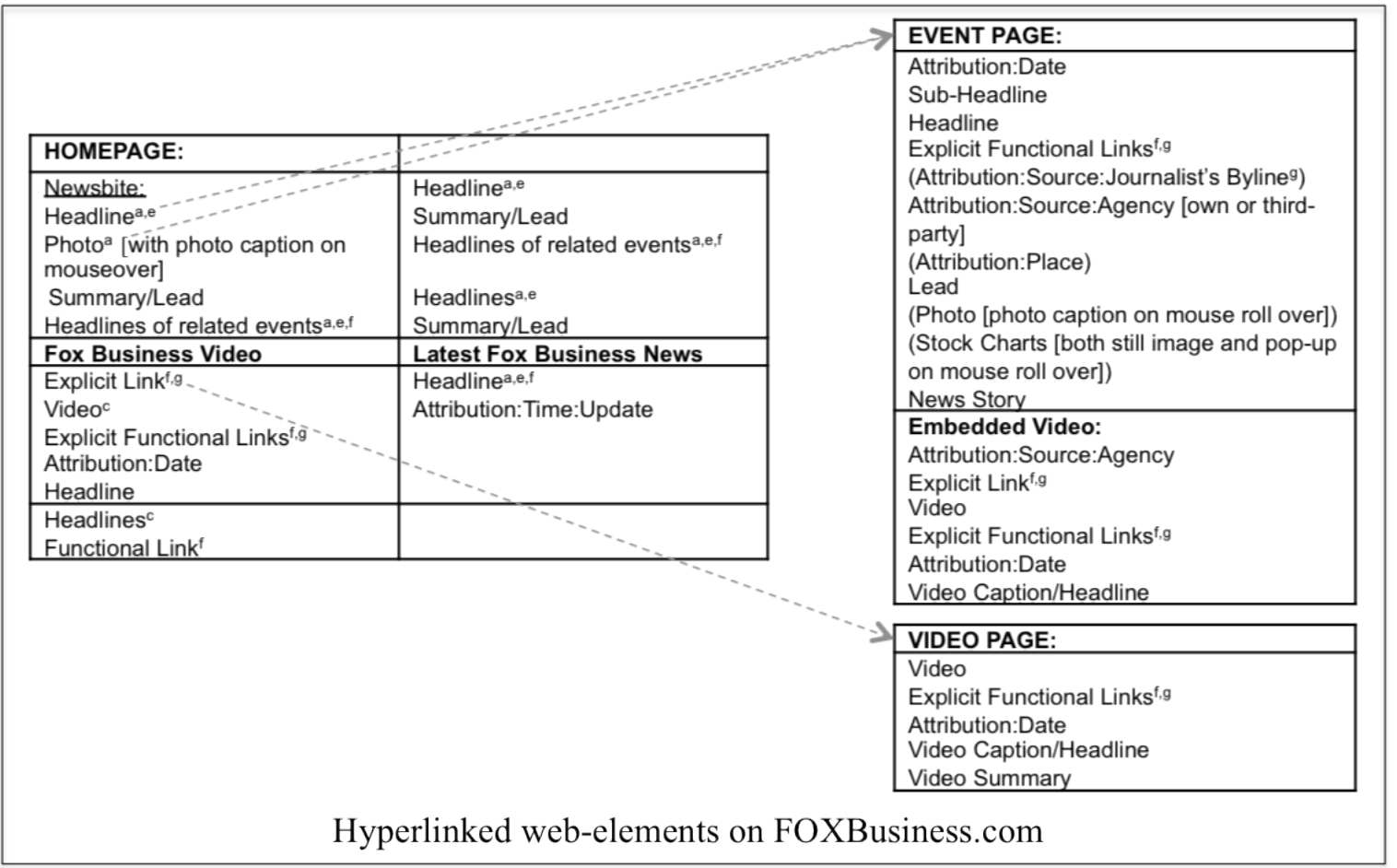

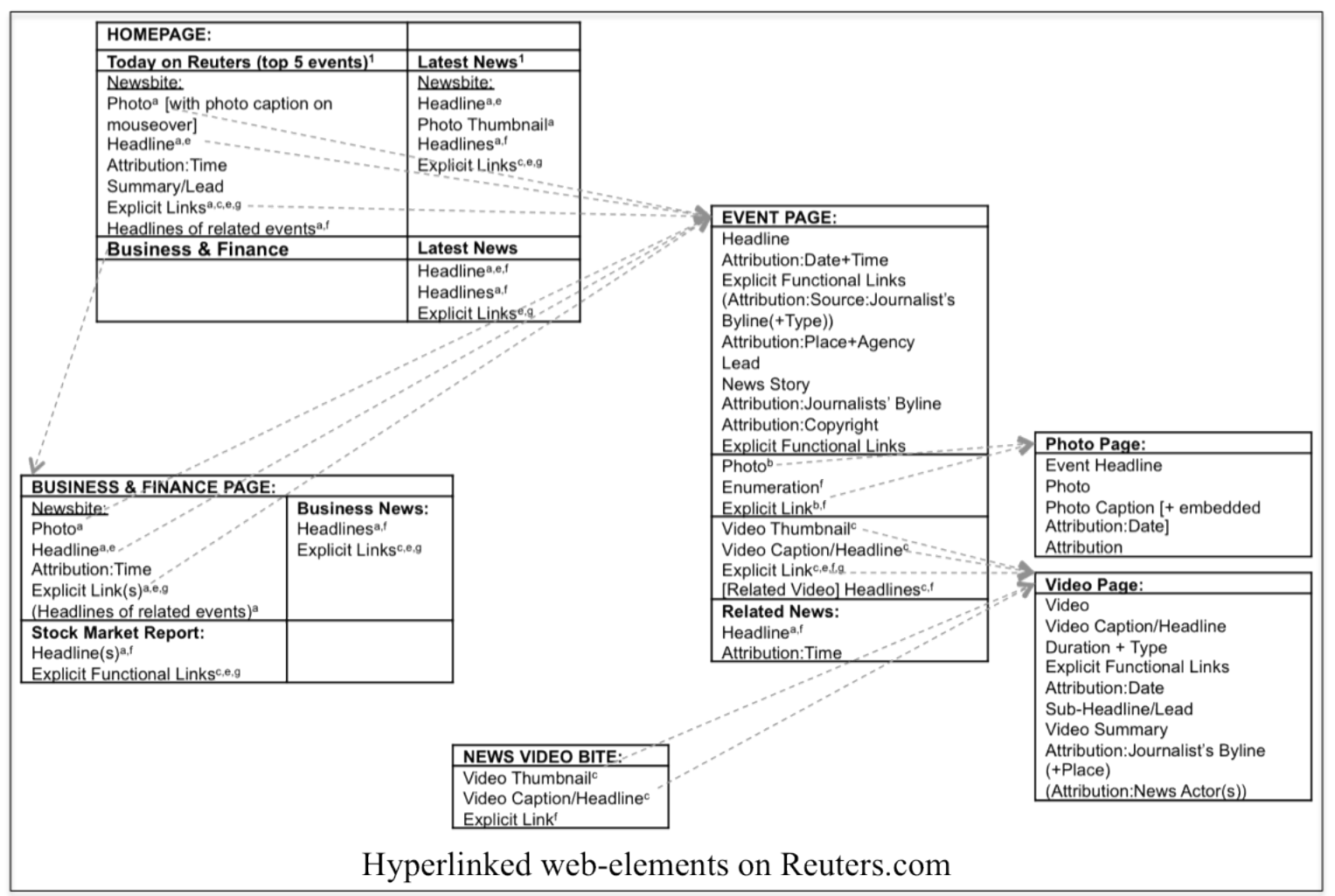

FIGURE 2.2b Hyperlinked web-elements on FOXBusiness.com and Reuters.com

While for many informative or educational on-line genres the principal method for signalling the relationships between webpage elements is visual hierarchy (e.g. see Djonov 
2005), in online business news discourse the existence of, or relationship between multiple representations of the same event across different media and webpage elements is not always made explicit to the reader or viewer. The hyperlinked or connectivity structure of separate web-page elements is outlined in Figure 2.2a-b.

The multiplicative nature of hypermediated business news discourse illustrates the complexities of on-line representations. They form the impetus for the analysis, which focuses on the multiple ways in which events, identities, and relationships are constructed and represented across different modes, media and networks, as discussed in Section 4. The following section outlines the main theoretical perspectives and conceptual models that motivate the research.

\section{The Representation of Business News Events: Underlying Theoretical Perspectives and Conceptual Models}

According to van Dijk (1988a), news topics (or events) are routinely subsumed within the headlines and lead paragraphs. Although the headline and lead paragraph are often seen as mutually dependent (see Bell, 1991; Iedema et al., 1994; White, 1997), it is generally the lead paragraph that is deemed most significant (e.g. see Bell, 1991, 1998; van Dijk; 1988a). Bell, for example, considers the Lead itself a complete 'micro-story', which will consist of all the main elements that constitute a single event (Bell, 1991, 1998). Consequently, the following analysis in Section 4.1 will focus primarily on representations of the news event as contained in the headlines and lead paragraphs of the hypermediated event.

The analysis is informed by Halliday's (1994 [1985]) systemic functional theory, which seeks to explain how people use language as a resource for meaning making, and how it is structured for such use. This structural organization realizes three kinds of meanings simultaneously, referred to as 'metafunctions', i.e.,

(a) the ideational metafunction, which is concerned with how we represent experience;

(b) the interpersonal metafunction, which expresses the speakers' or writers' role relationship with their audiences, and their attitude towards the subject matter; and

(c) the textual metafunction, which is concerned with how the text is organized and made relevant to its context. 
As Fairclough (1995) notes, events may be contextualized and recontextualized differently depending upon the "goals, values and priorities of the communication [medium] in which they are recontextualized. ... [D]iffering in their relative salience between different media texts, they may involve different aspects of the forms and meanings of texts, and may result in texts which are contradictory in the forms and meanings" (Fairclough, 1995: 48). The analysis thus aims to explore what is realized verbally as well as visually, what only verbally, what only visually, and so on (see van Leeuwen, 1996: 34; see also Bateman et al., 2003: 152; Lemke, 2002: 303), but also how a particular type of event is contextualized and recontextualized in different modes within and across media. It seeks to ascertain what particular representations and transformations it produces, and how these differ from other recontextualizations of the same event (e.g. see Fairclough, 1995: 41).

Iedema (2003) views such transformations as a form of resemiotization, which basically focuses on "how meaning making shifts from context to context, from practice to practice, or from one stage of a practice to the next (Iedema, 2003: 41). According to Iedema, the notion of resemiotization is meant to serve as an analytical tool for "(1) tracing how semiotics are translated from one into the other as social processes unfold, as well as for (2) asking why these semiotics (rather than others) are mobilized to do certain things at certain times" (Iedema, 2003: 29). In other words, the process of resemiotization is geared towards providing an answer to the question of "how, why, and which meanings become recontextualized" under certain conditions (Iedema, 2003: 40). It is essentially perceived as a supplementary approach to multimodal analysis for tracing how multimodal 'design' principles “re-appear" across different semiotic modes of representation (Iedema, 2003: 39). 


\section{Analysis}

\subsection{The Representation of Social Actors in Text and Image}

According to Galtung and Ruge (1965: 66), “[n]ews has a tendency to present events as sentences where there is a subject, a named person or collectivity consisting of a few persons, and the event is then seen as a consequence of the actions of this person or these persons" (cited in Montgomery, 2007: 7). As pointed out by Fairclough (1995: 39), however, in news discourse analysis, "[i]t is not simply the identification of participants that is of analytical interest; a key question is how participants' identities and relations are constructed". As such, the subsequent analysis deals with the question how the identities of news actors, i.e., the entities that feature as the participants in news stories, are constructed ideationally in business news discourse.

The analysis draws on van Leeuwen's $(1996,2008)$ framework for the representation of social actors, which offers a 'sociosemantic' inventory of categories for investigating how participants in social practices can be presented in English discourse. Although van Leeuwen's framework is grounded mainly in linguistics, he does suggests that "it becomes more and more pressing to be able to ask the same critical questions with regard to both verbal and visual representations, indeed, with regard to representations in all the 'media' that form part of contemporary 'multimedia' texts" (van Leeuwen, 2008: 25). The following analysis thus applies these 'sociosemantic' categories to representations of social actors in the verbiage and imagery of the hypermediated event.

According to van Leeuwen's $(1996,2008)$ framework, social actors may either be included or excluded in discursive representations. If they are excluded, this may be due to acts of suppression or backgrounding, which means that a "social actor may not be mentioned in relation to a given activity", but may be mentioned elsewhere in the text. In the case of backgrounding, actors are "not so much excluded as de-emphasised, pushed into the background" (van Leeuwen, 1996: 39). Acts of inclusion, on the other hand, are more concerned with the roles that social actors are accorded in representations (van Leeuwen, 1996: 42). As such, the analysis seeks to establish whether social actors are endowed with 
active or passive roles, that is, whether they are represented as Actor or Patient/Goal in material processes, or as Sayer in verbal processes.

For example, in the headlines on Bloomberg's homepage, main event page and related news page, an active role is accorded to the Bear Stearns prosecutors, who are represented as Sayer in a verbal process (Example 1a; see also Figure 4.1a, top left, marked [1]), whereby the Range of the verbiage on Bloomberg's homepage features as the Theme in the lead paragraph the 'More News' page and main story page (Example 1b; see also Figure 4.1a, top left, marked [2]).

(1) a. "Bear Stearns Fund Prosecutors Reveal 'Lot of Evidence' of Fraud"

b. "E-mail, witness statements and a money trail may help convict..."

In contrast, on the network's associated video page, it is the Bear Stearns' executive that is foregrounded (Figure 4.1a, top right, enlarged thumbnail, marked [3]). Here, the image represented in the video thumbnail depicts a dispositive material process of action of 'doing to' (see Halliday, 1994: 111), with the peripheral figures (i.e., the federal agents) represented as the Actor or Agent and the central figure (in this case, Ralph Cioffi, one of the alleged perpetrators of the financial crime) portrayed as the Goal or Medium (Figure 4.1a, top right, enlarged thumbnail, marked [3]). According to Kress and van Leeuwen (1998: 196), for something to be presented visually as the "Centre means that it is presented as the nucleus of the information". The 'nucleus of the information' that is foregrounded in this visual representation of the event is clearly the Goal or Medium ${ }^{3}$, in other words, Ralph Cioffi, the alleged perpetrator of the financial crime.

The active role of the social actors is most clearly foregrounded in cases where the activation is realised by 'participation' through the invocation of grammatical participant roles (see van Leeuwen, 1996: 44; 2008: 33). Nonetheless, the majority of textual representations on the networks' webpages present the Goal or Medium as the Theme in the headline and lead paragraph, whereby the Actors or Agents are either backgrounded or entirely excluded from the discourse. In other words, the perpetrators of the alleged financial crime, i.e., the two former Bear Stearns executives, are represented as being at the receiving end of the portrayed action, while their prosecutors are excluded or backgrounded, often in 
the form of finite-less nominal groups in the headlines. In fact, this seems to be the "default" micro-structure that has been adopted by these networks in the multimodal representation of this event (see Figure 4.1a-b, marked [4]). The videobite headlines on CNBC.com (Figure $4.1 \mathrm{~b}$, bottom, marked [5]), in fact, exclude, or rather background, all types of social actors and social action by way of nominalization, thereby abstracting or objectivating the underlying material process of action, representing it, in van Leeuwen's (2008: 55) terms, as a generalized and intangible 'phenomenon' instead. Only two representations feature the two accused fund managers as the Actor or Agent in the alleged financial crime (Example 2a-b; see also Figure 4.1c, top left, marked [6]).

(2) a. "Two former hedge fund managers at investment bank Bear Stearns defrauded investors..."

b. "...they ran two hedge funds investing in subprime into the ground..."

Similarly, the agency function of their prosecutors is rarely acknowledged (Example 3a-b; see also Figure 1.4c, top right, marked [7]).

(3) a. "Former hedge fund managers Matthew Tannin and Ralph Cioffi ..."

b. "...as they charge these two former hedge fund managers..."

Kress and van Leeuwen (2001) believe that the visual component of a text is generally independent of language. Although it may be closely associated with the verbal text, they argue, it is not necessarily dependent upon it (see Machin and Niblock, 2006: 144). The composition of the visual image on FOX's main event page (Figure 4.1c, bottom) is identical to the visual representations of the event as displayed by other networks (e.g. see Figure 4.1ab). In the accompanying verbiage in the photo caption, however, the federal agents are thematized and depicted as the Actor in an intransitive material process, with the Bear Stearns executive backgrounded linguistically as a Circumstance of Accompaniment (Example 4a; see also Figure 4.1c, bottom, marked [8]).

(4) a. "Federal agents exit 26 Federal Plaza with handcuffed former Bear Stearns hedge fund manager Ralph Cioffi." 


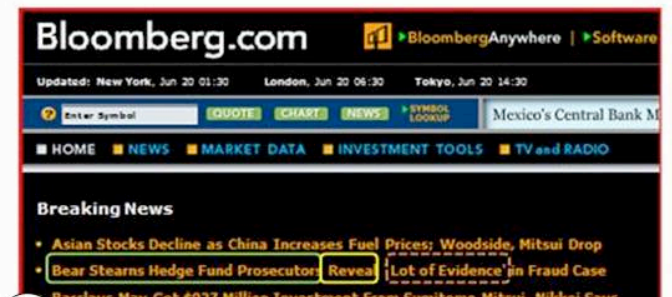

1

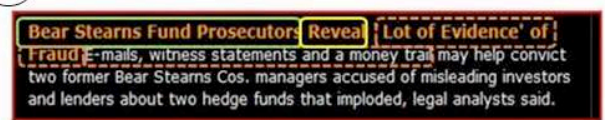
\begin{tabular}{|l|}
\hline Bear Stearns Fund Prosecutors Reveal Lot of 1 \\
\hline Evidence' of Fraud
\end{tabular} By David Voreacos

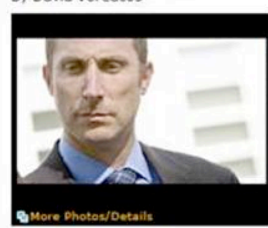

an. 20 (Bloomberg) $-(\bar{E}$-màilš, 2 Witness statements and a money trat Stearns cos. managers accused isleading investors and lenders legal analysts said.

Ralph Cioffi, 52, and Matthew Tamnin, 46 , were charged yesterd Thing while knowing investments in subprime mortagaes could cause their collapse. U.S. prosecutors claimed the men lied about liquidity, redemption requests, and their own nvestments before
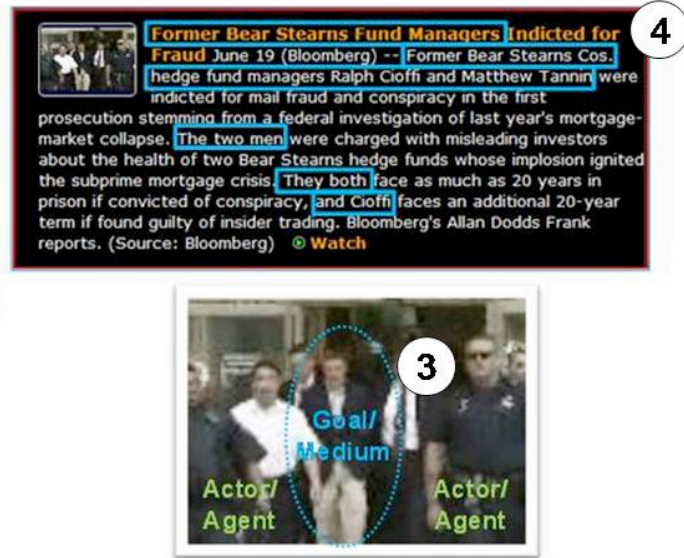

(thumbnail enlarged)
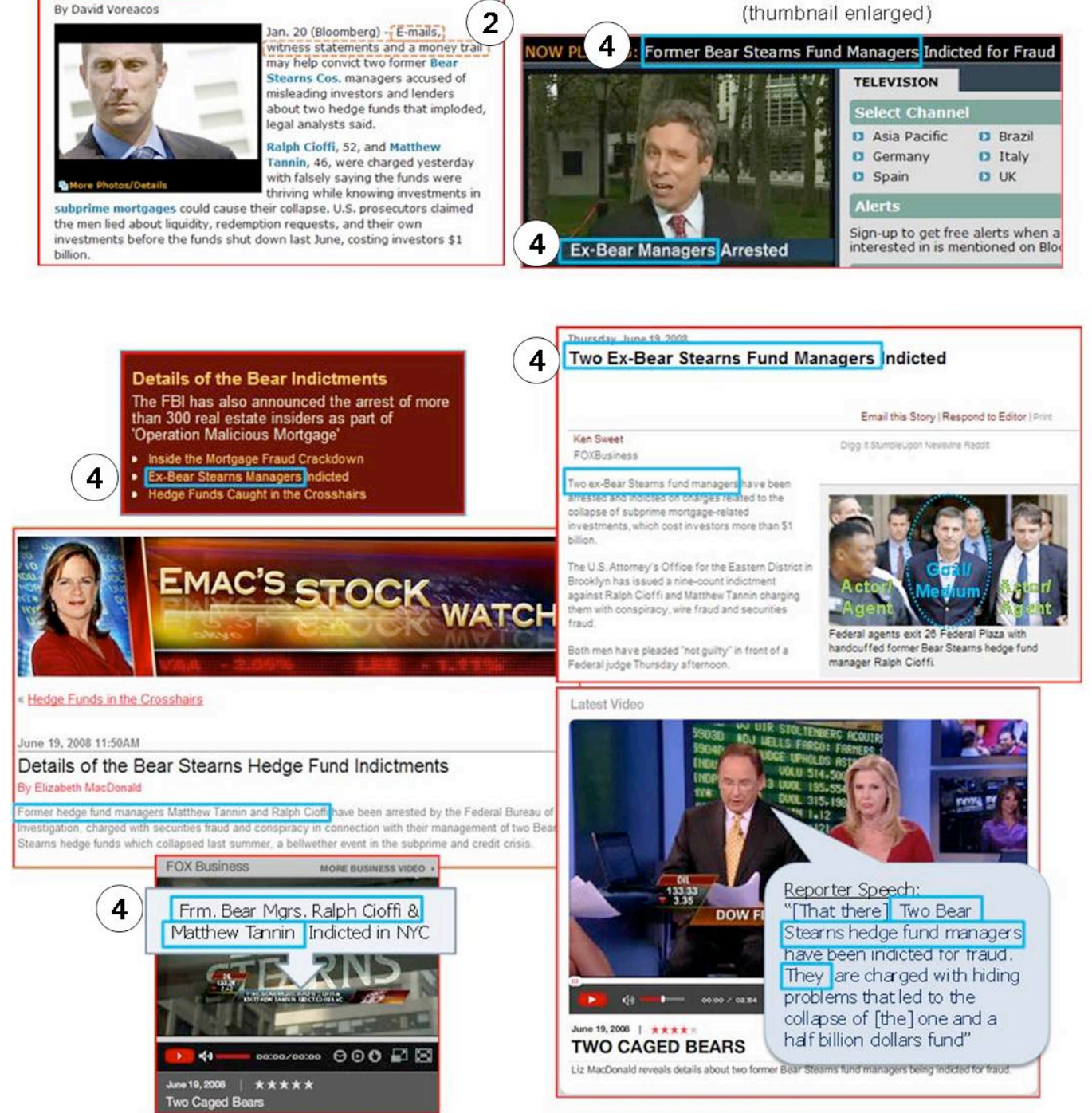

FIGURE 4.1a Representations of Social Actors in Text and Image 


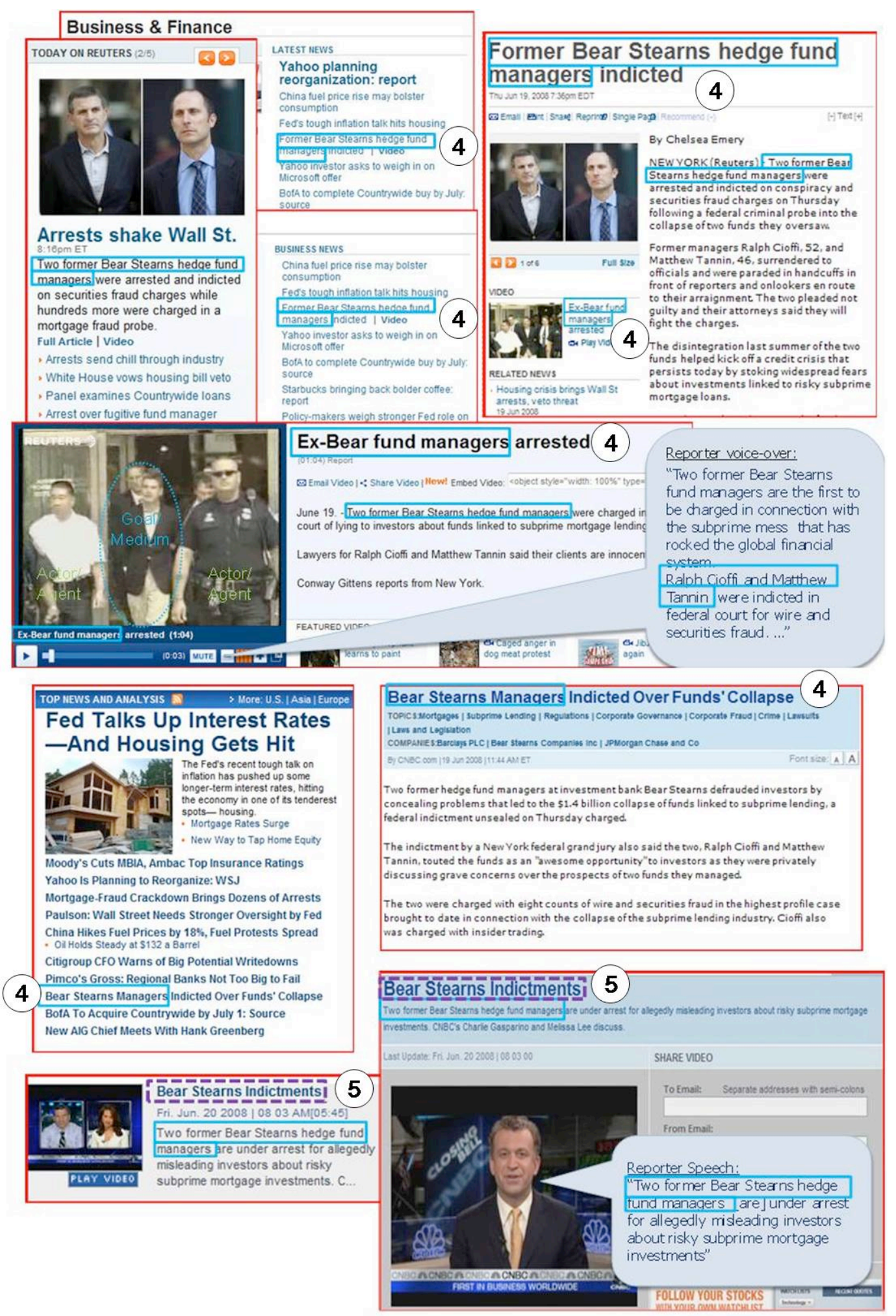

FIGURE 4.1b Representations of Social Actors in Text and Image 

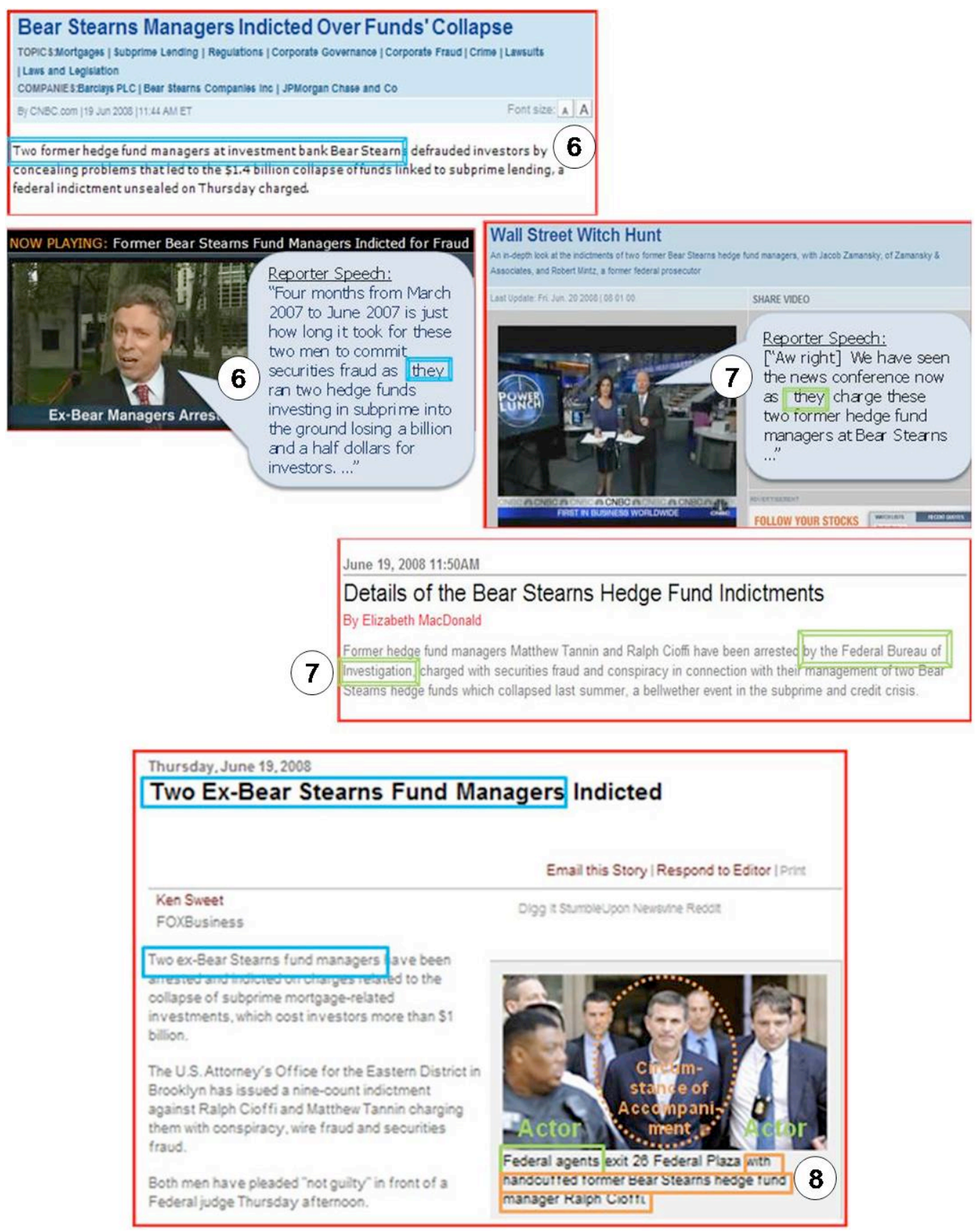

FIGURE 4.1c Representations of Social Actors in Text and Image

The action portrayed in the photo caption is thus not synonymous with the action alluded to in the headline and lead paragraphs. The resulting disjunctive re-contextualization of the event may perhaps be attributed to the composite character of traditional news production processes, whereby photo captions are routinely inserted by photo editors, whereas headlines are generally written by subeditors (e.g. see Bell, 1991: 41). Such variable representations may offer an insight into the underlying design principles that motivate the multimodal construction of this event. 


\subsection{The Representation of Social Interactive and Discursive Processes}

The analysis of this event is, of course, not only concerned with how social actors are referred to and represented in terms of their ideational meaning potential through text and image, but also focuses on the construction of identity in terms of interpersonal relations. In other words, it deals with the types of social and personal identity that are set up in media discourse for newsmakers, newsworkers, and target audiences, through social interactive and discursive processes.

\subsubsection{The Construction of the Newsmaker in Discourse}

As pointed out by Bell (1991: 194), newsmakers rarely act in news discourse; they talk (see also Montgomery, 2007: 3). This stance is confirmed by Scollon (1998: 245), who posits that "the role of the newsmaker is not to create events, but to provide statements". Scollon (1998: 245), in fact, defines newsmakers as "figure[s] crafted out of the words and characterizations of the journalist" by means of attribution, which focuses on (1) the ways in which speech (or its contents) are attributed to speakers or agents, (2) the characterization (or rather construction) of the agents of speaking, and (3) instances of polyvocal or heteroglossic voicing (Scollon, 1998: 219).

Indeed, in most instances in this case study, where thematized, the public prosecutors and federal agents are featured as Sayer in a verbal process ${ }^{4}$ (Figure $4.2 \mathrm{a}$ ). The same applies to the lawyers for the accused, which is, in fact, mediated multiply across media in the form of actuality footage in the associated video- and sound-bites. In broadcast video, this identity is often constructed multiply and multimodally, but it is almost always mediated exclusively by the newsworker. For example, while the public prosecutors and lawyers for the accused Bear Stearns' executives are granted the right to address the viewer directly visually and/or verbally in actuality footage (whereby their authority to speak is mediated multiply through on-screen identification as well as verb-categorization), the newsmakers' discursive act is, in every case, framed explicitly by the reporter. As such, as Scollon (1998: 238) has noted, "it remains a story of the reporter, not of the newsmaker". 

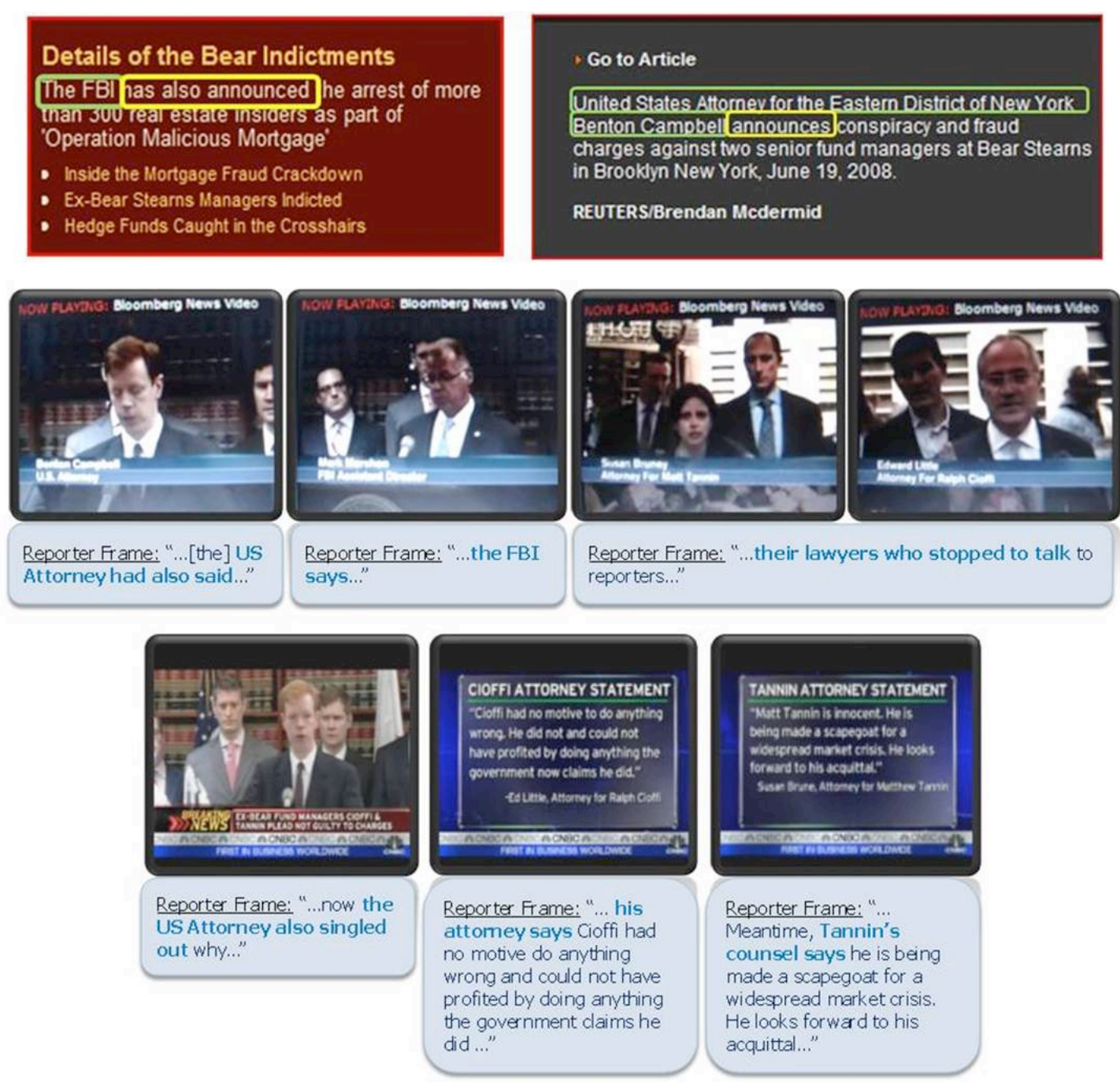

FIGURE 4.2a Representations of Newsmakers: 'Sayers' in verbal processes

In fact, much of business news discourse tends to be mediated in the form of broadcast interviews with newsmakers (see Clark et al., 2004: 293,300). In this regard, Clayman (1991) offers a viable model for the description of interpersonal roles that are typically constructed for newsmakers in news interview openings. Drawing on the notions of topical relevance principle and the principle of recipient design, Clayman (1991: 60-61) argues that topical relevance "can be seen in the methodical ways that interviewees are aligned as qualified to speak on [a] focal matter" (see also Haddington, 2006). He proposes that the opening segments of broadcast news interviews may, in fact, serve as mechanisms, not only for projecting the agenda for the news interview at hand, but one that grounds it in the newsworthy events of the day (Clayman, 1991: 48-49). He notes, for example, that interviewers often start the interview sequences by encapsulating some newsworthy item in a general statement or 'verbal headline'. According to Clayman's observations, the interview 
headline itself may be presented in two alternative formats, i.e., it may take the form of either a news announcement, whereby "the interviewer straightforwardly reports some news item", or an agenda projection, in which the news item is presented as the topic for discussion or debate (Clayman, 1991: 50-51).

For example, in the embedded video in CNBC's main event page, the news announcement, or presentation of a 'news kernel' - which in Montgomery's (2008: 84) terms is conceptualized as a summary of the key facts of news item (Example 5a). This is followed by an agenda projection in which the news event is re-contextualized as the topic for the debate that is to follow (Example 5b), which is also projected in the on-screen display and the video caption 'Witch Hunt on Wall St.' (see Figure 4.2b).

(5) a. News Kernel: "[Aw right] we have seen the news conference now as they charge these two former hedge fund managers at Bear Stearns managers Ralph Cioffi and Matthew Tannin arrested at their homes this morning and escorted to Federal Court..." (Figure 4.2b, callout, marked [1]).

b. Agenda Projection: "Are the two managers scapegoats, or are they the first two criminals to face justice in the subprime debacle?" (Figure 4.2b, callout, marked [2]).

It effectually re-contextualizes and transforms a news item that, in White's (1997) terms, is grounded in a material event on the network's main event page (Figure 4.2b, top left, marked [3]) into one that is grounded in a communicative event ${ }^{5}$, which is concerned not with fact but with the statements and opinions of some authorized sources ${ }^{6}$, whose constructed identity in this case is that of a certified expert.

According to Clayman (1991: 62), certified experts are generally characterized as having specialized knowledge relevant to the focal news item without having encountered it first-hand, especially in situations where their expert status is displayed through descriptions of organizational or institutional affiliation, which entitles them to speak from the basis of privileged knowledge, although their neutrality on the matter may not be necessarily guaranteed $^{7}$ (see Montgomery, 2007: 176). Scollon argues that the question of identity of newsmakers needs to be understood not just as a matter of negotiating dialogic positions for 
them, but as "accounting for their authority" to 'speak' (see Scollon, 1998: 174). He notes that the "difference in the ways the voices of reporters and those of newsmakers enter the discourse is that reporters are simply and directly delegated the right to speak... whereas newsmakers are evaluated or characterized in the process of giving them voice" (Scollon, 1998: 217). In terms of van Leeuwen's $(1996,2008)$ framework (outlined in Section 4.1), the newsmakers in this case study are categorized by means of functionalization; in other words, their 'expert' authority is established in terms of something they do, such as their occupation, or the role they previously held, which authorizes them to comment or voice their opinion on the case at hand (Figure 4.2b, marked [4]).

Accordingly, the constructed identity of participants in news interviews and their perceived capacity to comment on a certain event or issue is largely dependent upon the implicit role that is constructed for them by the newsworker (see Clayman (1991; see also Haddington, 2006; Thornborrow, 2001), which also guides the character of the discussion that is to follow. The introduction of certified experts, according to Clayman (1991: 63), usually prefigures an informational interview, where official insiders are called upon to provide contextual background information to an event, or to spell out the implications of a development (see Montgomery, 2007: 170), whereas advocates are expected to defend a particular point of view in a debate interview. In the CNBC video entitled 'Wall Street Witch Hunt' (Figure 4.2b) we actually see a conflation of the two (Example 6a-b).

(6) a. Informational Interview: "An in-depth look at the indictments of two former Bear Stearns hedge fund managers with Jacob Zamansky, of Zamansky \& Associates, and Robert Mintz, a former federal prosecutor." (Figure 4.2b, video summary/lead, marked [4])

b. Debate: "Joining us now with their respective views on this..."

(Figure 4.2b, callout, far right centre, marked [5])

Clayman (1991) and Scollon (1998) assert that only journalists have the right to control and regulate the topic of the discussion, which is demonstrated in this case by the female anchor, who half-way into the discussion, explicitly reformulates the agenda for the newsmakers by way of self-reflexive reference (Example 7a; see also Figure 4.1b, bottom, marked [6]). At the same time, the iconic gesture she performs at this point (outlining a question mark) co-references the polar-interrogative character of the interview in progress. 
(7) a. Agenda Reformulation: "We are running a lower third on the screen that says Witch Hunt on Wall Street with a question mark. What do you think? Is this a witch hunt or no?”
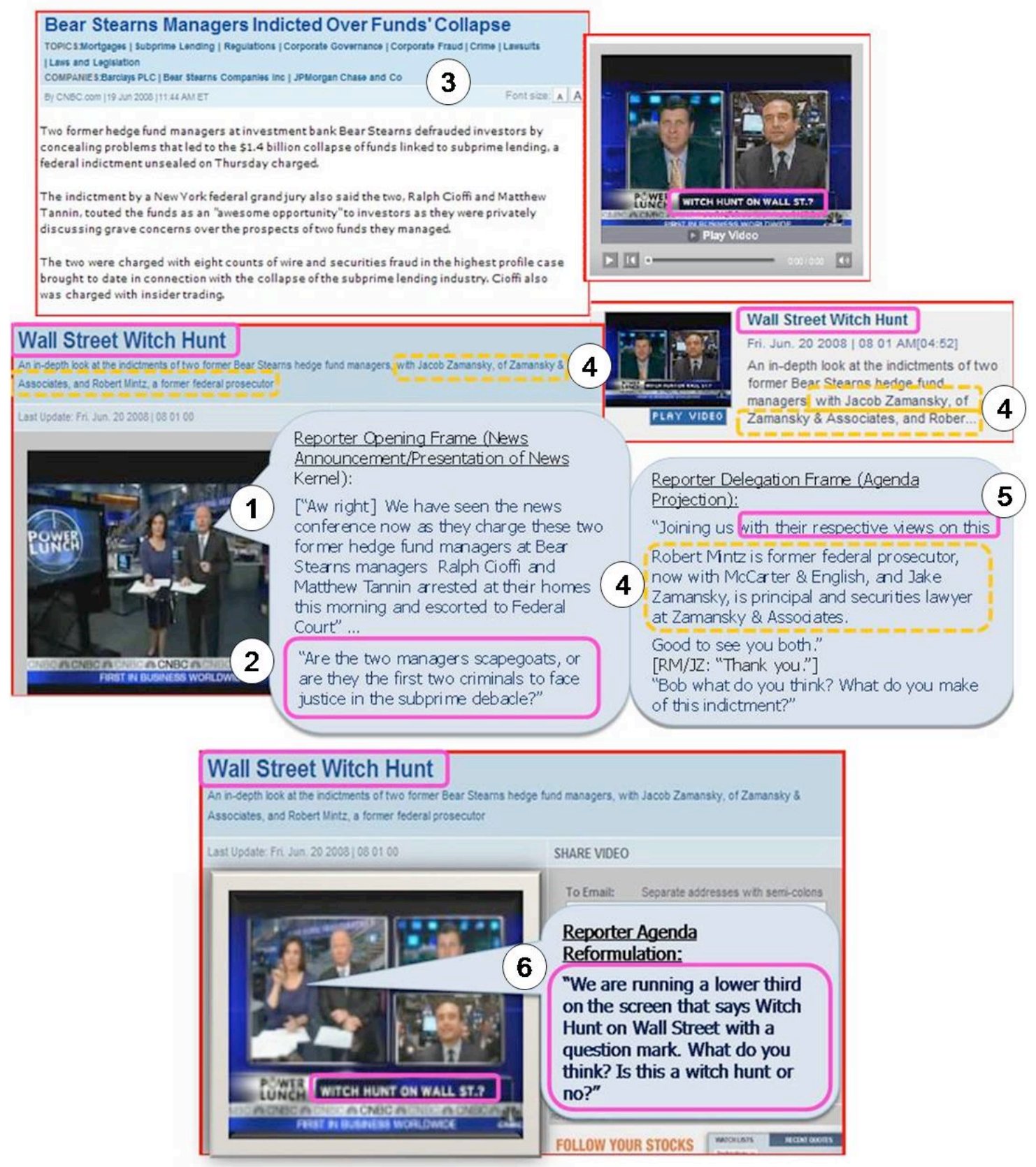

FIGURE 4.2b Representations of Newsmakers in News Interviews: Certified Experts, Agenda Projections and Agenda Reformulations 


\subsubsection{The Construction of the 'Expert' Newsworker}

While much of existing research on news discourse deals with the constructed persona of the news actor or newsmaker, in broadcast video newsmakers are not the only participants that feature as certified experts. For instance, Machin and Niblock (2006: 30) as well as Montgomery (2007) comment on the rise of the 'journalist-as-expert', where specialist reporters and editors are themselves called upon as sources, which is particularly prevalent on dedicated financial and business news channels, where financial journalists and commentators are often seen as 'market players' in their own right (Clark et al. 2004: 293).

The discourse structure of such interactional exchanges with affiliated news sources, however, differs substantially from interviews with external parties. Although Montgomery (2007: 128-129) observes that editors are generally distinguished hierarchically from reporters or correspondents by enjoying greater topical freedom, which allows them to speak "almost separately from the institution, embodying in their own voice and person an independent insight and authority", in this particular case study, the right to speak tends to be delegated to the 'journalist experts' by means of nomination in the video summary and reporter voice-over, as well as by way of relational identification and affiliation with the news agency through linguistic acts of possession (see van Leeuwen, 1996: 54-57) (Example 8a-b; see also Figure 4.2c, marked [1]).

(8) a. "CNBC's Charlie Gasparino and Melissa Lee discuss."

b. “...We first go to CNBC's Mellissa Lee...”

As noted by Scollon (1998: 249), newsworkers routinely position themselves in relation to "others within their own community of practice and in doing so construct for themselves the crucial journalistic identities of editors, reporters, presenters, owners and the rest”. Scollon's $(1998: 159,164)$ posits that the identity of newsworkers is negotiated mainly through the Opening-, Closing- and Delegation Frames, i.e., the particular ways in which a news event is framed dialogically within the broader framework of a television news programme, or news video sequence in this case. Scollon's (1998) model offers a means to account for the multiple ways newsworkers' (as well as newsmakers') identity is constructed around the "hierarchy of social practices framing of channel, relationship (or person identity) 
and topic" (Scollon, 1998: 184). This may be realized through naming, on-screen characters, video identification, and visual-verbal terms of address (see Scollon, 1998: 159-184).

Accordingly, despite the fact that the presentation of the event is contextualized linguistically as a 'discussion' in the video summary (Figure 4.2c, second from top, marked [2]), the discursive structure of this video sequence follows the traditional presentational structure of a 'live two-way' or, this case, actually a 'four-way' affiliated news interview, as identified by Montgomery (2007). Presenters simply and directly delegate the right to speak to each other in sequential order, i.e., where the presentation of the 'news kernel' or verbal headline (Figure 4.2c, top, marked [3]) is followed by a standard news report of the event (with actuality footage) delivered by CNBC's Mellissa Lee, which is succeeded by a commentary or opinion report by On-Air Editor Charlie Gasparino, whose opening statement closely mirrors the presenter's initial agenda projection that encapsulates how this particular event is going to be contextualized for the viewer (Example 9a-b; see also Figure 4.2c, marked [4]), and who, in turn, delegates the right to speak to another (unidentified) presenter in another studio, who finally brings the presentation of the news video to a formal close, with direct address to camera (Example 9c; see also Figure 4.2c, bottom, marked [5]).

(9) a. Reporter Delegation Frame: "On-air editor Charlie Gasparino [is] looking at the broader implications for the rest of the financial industry."

b. Commentary/Opinion Report: "I've been spending a lot of time talking with Wall Street executives and uh uh lawyers/attorneys out there about what are the broader implications of this case..."

c. Reporter Closing Frame: "Charlie, I think you made a lot of very good points there. Thanks so much. Charlie Gasparino in New York." 

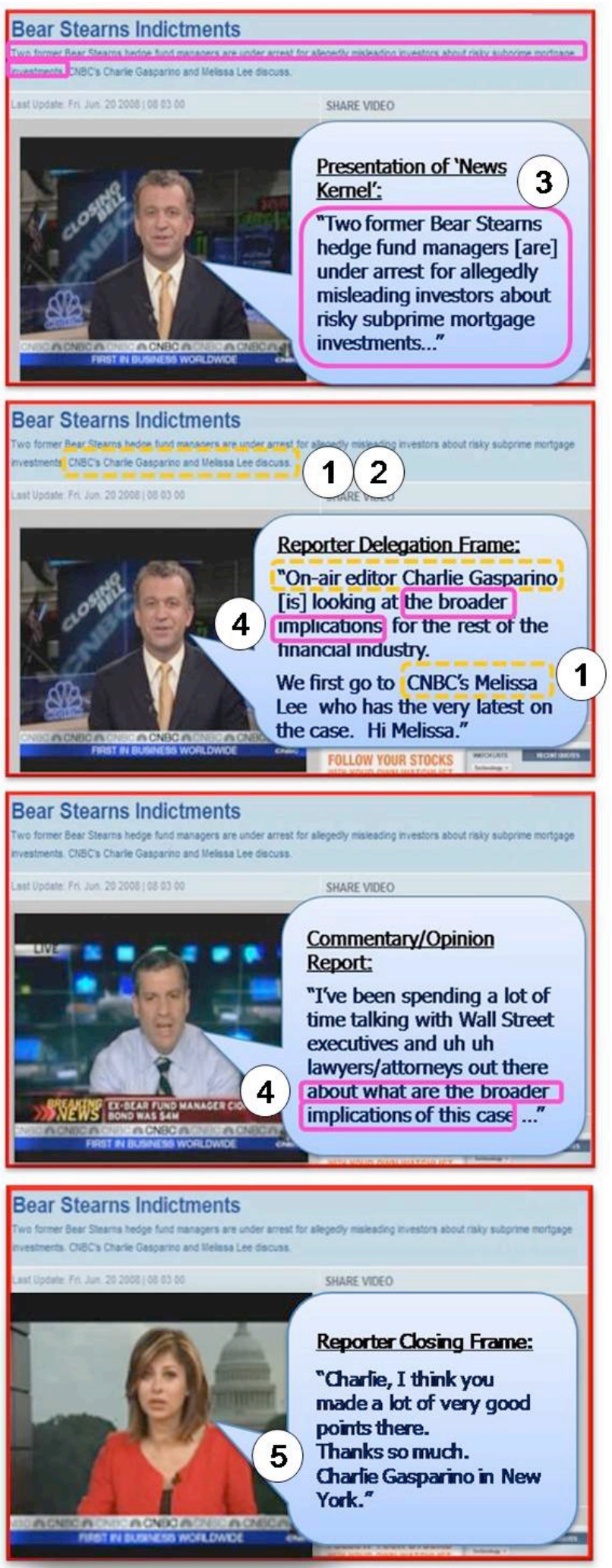

FIGURE 4.2c The Construction of the 'Expert' Newsworker in Affiliated News Interviews 


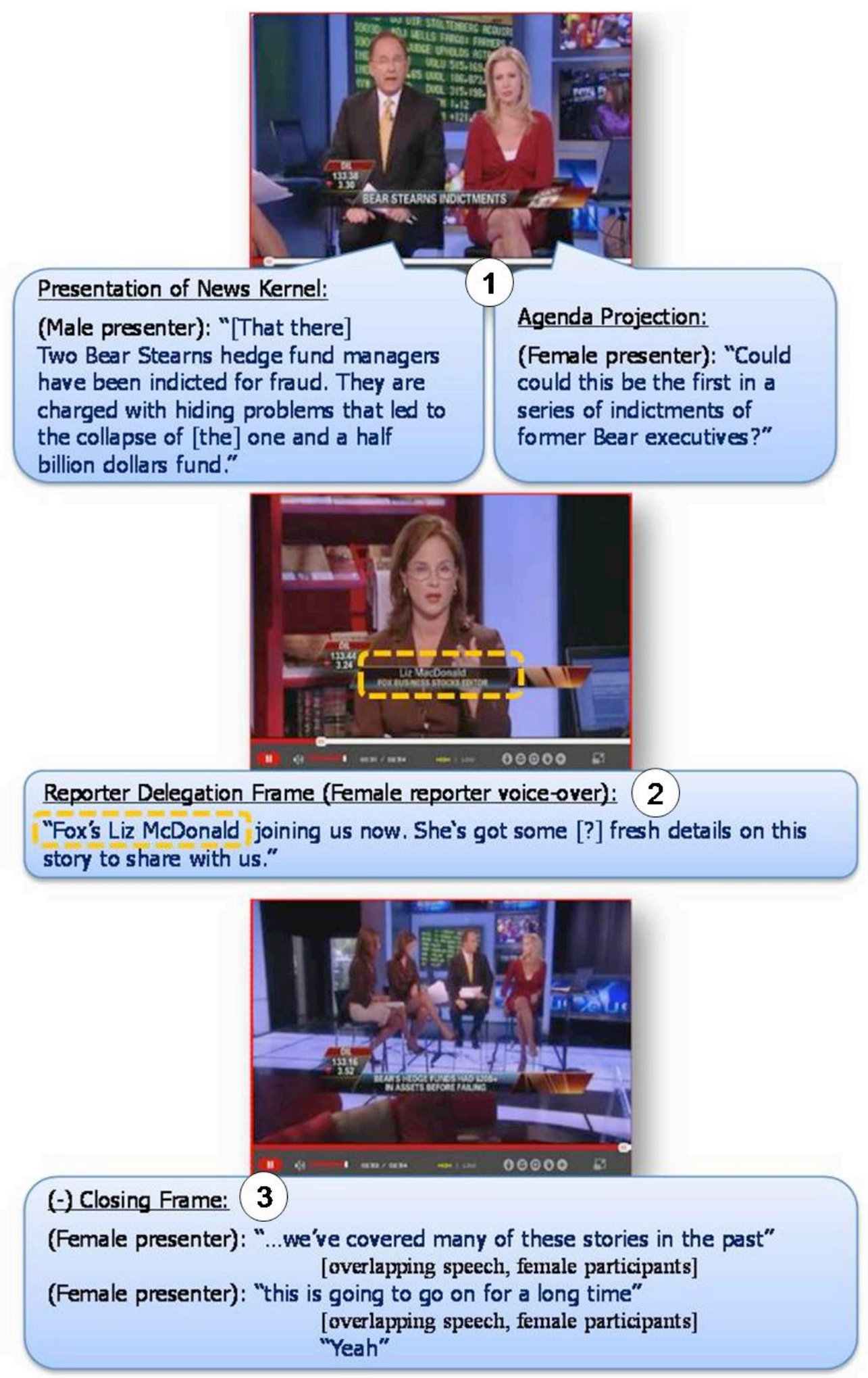

FIGURE 4.2d The Construction of the 'Expert' Newsworker in Round Table Discussions 
A rather different discursive format, however, is at play in the FOXBusiness video portrayal of this event. At the outset, the discourse structure seems to mirror that of an informational or debate interview, whereby the the news announcement, or news presentation by the male anchor is followed by an agenda projection by the female presenter (Figure 4.2d, top, [1]). Similarly, the reporter delegation frame is near identical to the one observed in CNBC's video sequence, whereby the right to speak on the focal matter is delegated to the network's 'expert 'editor by way of relational identification with the news agency (Figure $4.2 \mathrm{~d}$, middle, marked [2]). What follows, however, marks a different type of "news subsidiary', what I conceptualize as a 'round table' discussion. An affiliated 'round table' discussion is relatively unstructured with a high degree of topical freedom, fluid speakerturns and interactional exchanges characterized by many instances of overlapping speech and open-ended discursive frames. In other words, in this particular instance, the round table discussion simply ends without being brought to a formal close by the anchor or presenter (Figure 4.2d, bottom, marked [3]).

\subsection{The Position of the Audience and its Ideological Implications}

(Tele)visual representations of social interactive processes, of course, also have implications for the ways in which the discourse situates another type of participant this case study has not considered this far: the consumer of news, the audience.

Budd et al. (1999: 124), for example, see network news as an instantiation of a hierarchical discourse of authority. "Whatever else network news may tell us, its very way of presenting itself - and of hailing or positioning us - reinforces its hierarchy of authority and its deliberate confusion of the gravity of the news with the constructed personality of its anchors and correspondents" (Budd et al., 1999: 124). The power of visual address, they claim, "is key” to the networks' symbolic hierarchy of authority (Budd et al., 1999: 125).

While the former discourse types (as elucidated in Figure 4.2c) seem to be aimed at and contextualized primarily for a viewing audience in terms of televisual processes of production, with many close or medium close shots of the anchor or presenter in direct address to the camera, thereby reducing the social distance to the viewing audience, the round-table discussion, on the other hand, situates the viewer as a mere observer or spectator who is listening in or eavesdropping on the presenters' conversation, by alternating 'point-of- 
view $^{8}$ and over-shoulder shots at medium distance with long shots of all participants inclusive of the studio backdrop or setting, which, as result, increases the social distance to the viewer.

The way audiences are positioned in televisual news discourse, however, has broader implications for the ways we are addressed by and 'experience' the news. Montgomery (2007: 130), for instance, maintains that the discourse of the news subsidiary or affiliated interview is very different from the discourse of presenting and reporting. He distinguishes between discourse types that are designed to be 'overheard' by the audience and discourse types that are directly and solely addressed to it, such as headlines, for example (Montgomery, 2007: 30). Masterman (1985) observes that a text's mode of address, its setting and its format, opens up social spaces that are linked to ideological positions that influence how we make sense of experience. In the opening frames of news reports "we are addressed by a newsreader who looks directly at the camera and delivers 'the facts'. Each viewer is given the role of direct addressee" (Masterman,1985: 229). Conversely, in a televised interview, the viewer's position changes: "We are no longer directly addressed, but eavesdrop, watch and judge. The different positions assure us that some aspects of experience must be accepted (facts), whilst others (opinions) require our judgment” (Masterman, 1985: 229-230; cited in Ellsworth, 1997: 25).

Van Dijk (1988b: 124) maintains that one of the central ideologies of traditional Western journalism is that fact and opinion should not be mixed (see also Bell, 1991: 13). Nonetheless, the above analysis has shown that the ideological positions that are thus created by business news networks involving new media are more fluid and complex, and perhaps not always easy to separate, especially for the viewing audience. In Scollon's (1998: 188) opinion, the primary audience of most news discourse is, in fact, other journalists, where viewers are positioned as mere spectators in the journalist's 'conversational game' (Scollon, 1998: 185-186). Clark et al. (2004: 293) see this game being enacted through "the rule of theatricality: money and finance have an explicitly performative character. They have to be scripted and acted out". As Clark et al. (2004: 297-298,303) observe, these newly emergent media practices owe more to entertainment television than to 'serious and sober' financial journalism which, they claim, has been transformed into a form of daily entertainment that is dominated by a cacophony of people, noises, and a constantly changing array of images and information. In other words, business news has become a daily media spectacle. 
The increasing shift towards conversationalization, has, of course, been observed by other media theorists and researchers. Fairclough (1995: 10-11), for example, comments on the tendency of the news media becoming increasingly 'conversationalized' due to mounting commercial pressures and competition, which has implications on the way the news media represent themselves. The increased conversationalization of the news media is said to be reflected in the "development of a 'public colloquial' language...a public language for use in the media which is modelled to varying degrees and in varying ways upon the practices of informal, colloquial, conversational speech" (Fairclough, 1995: 38). In particular, this appears to be manifested in the revolutionized interviewing practices, which have changed from previously formal interactions between reporters and figures of authority to more informal and conversational interactions (Fairclough, 1995: 50-51). Not only does this change in media practices reflect an attempt to increase audience appeal, but one which affects both the content and style of delivery (see Fairclough, 1995: 42-43; see also Clark et al., 2004: 293).

Some media researchers, however, view these changing media practices positively. Montgomery (2007: 71), for example, opines that the emergence of network news has produced discursive models that are more 'relaxed', 'open' and dynamic, and geared towards greater naturalism, compared to more traditional styles of news presentation (Montgomery, 2007: 196), which, of course, also has had an impact on the ways business news are represented by 24 -hour financial news networks. These changes in discursive practices can in fact "breathe life" into business and financial news, whose appreciation requires a minimum level of financial literacy (see Clark et al. 2004: 298). As a result, business and finance news becomes increasingly accessible to a wider circle of general audiences, who may not possess the critical insights and skills to separate opinion from fact. 


\section{Conclusion}

This exploration of multimodal, multimedia representations of a business news event on the internet has shown that there seems to be a high level of consistency in the way the event is represented textually by the different networks in the headlines and lead-paragraphs, especially in the way social actors are portrayed visually as well as verbally. However, salient variations in style start to emerge in the way the event is mediated televisually. The presentation of fact and opinion starts to converge, and is often recontextualized for the discourse participants directly involved in the social practice of news reporting, presenting and interviewing, as well as the viewing or overhearing audience. Consequently, the underlying ideological assumptions and implications that may be encoded in the ways business news networks choose to represent and position themselves, their sources, and their target audiences through electronically mediated forms of business news discourse, are complex and multifaceted, and difficult to conceptualize without resorting to the insights of more than one discipline or research tradition.

By combining discourse analysis, social semiotics, and other interdisciplinary perspectives, this article has endeavoured to present a holistic view of the complex ways business news are mediated on the internet and television by continuous 24-hour networks, which may form the impetus for further investigation and research. It is hoped that by building on and expanding existing multidisciplinary frameworks, concepts and theories, future, more in-depth research into the medium of business news discourse will lead to the development of a viable integrative framework and theory that may expand our - as yet limited - understanding of the complex meaning-making processes that are at play in the emergent genre of hypermediated business news discourse as represented on television and the internet. 


\section{Notes}

1 The Events in the World project is supported by the Singapore National Research Foundation Interactive Digital Media R\&D Program, under Research Grant NRF2007IDM-IDM002-066.

2 A 'newsbite' can be defined as a combination of thumbnail image, headline, and summary-lead, and is typically found on the homepages of on-line news genres (e.g. see Knox, 2009).

3 A role that in Discourse Analysis is often referred to as the Patient, although in my analysis I will be using Halliday's terms of Goal or Medium.

4 Bell (1991:206-207) notes that there is a relationship between who is speaking and the speech verb used, whereby 'say', which is considered to be a 'neutral' speech verb, is often used to attribute verbal processes to a range of 'credible' sources.

5 According to White (1997:106), event stories that are grounded in a material event purport to describe the events at first hand, "to present a largely unqualified, unmodified account of what happened". Issues reports, on the other hand, which are grounded in a communicative event, do not describe the actions and states of affairs first hand, but rather 'project' them "via the process of reporting the statements of some authorized source" (White, 1997:106). As such, issues reports commonly deal with statements and claims, not 'facts'.

6 In this particular video sequence, the event is effectively resemiotized as a mental process of cognition, that is, the certified experts are asked explicitly what they 'think' and what they 'make of this' event (see callouts, Figure 4.1b).

7 Which is indeed the case in this video sequence, as one of the interviewees freely admits that he is representing investors who have lost substantial amounts of money as result of the hedge funds' collapse.

8 According to Bordwell and Thompson (2004:299), the structures set in place by the shotreverse-shot or $180^{\circ}$ system operate in such a way to create the illusion that the represented participants are looking at each other, although only one participant is shown in each frame. 


\section{References}

Bateman, J., Delin, J. and Henschel, R. (2007) 'Mapping the Multimodal Genres of Traditional and Electronic Newspapers', in T.D. Royce and W. L. Bowcher (eds) New Directions in the Analysis of Multimodal Discourse, pp. 147-172. London: Lawrence Erlbaum Associates Inc.

Bell, A. (1991) The Language of News Media. Oxford, UK; Cambridge, MA: Blackwell.

Bell, A. (1998) 'The Discourse Structure of News Stories', in A. Bell and P. Garrett (eds) Approaches To Media Discourse, pp. 64-104. Oxford; Malden, Mass.: Blackwell

Bordwell, D. and Thompson, K. (2004) Film Art: An Introduction. Boston: McGraw-Hill.

Budd, M., Craig, S. and Steinman, C. (1999) Consuming Environments: Television and Commercial Culture. New Brunswick, New Jersey: Rutgers University Press.

Clark, G.L., Thrift, N. and Tickell, A. (2004) 'Performing Finance: The Industry, the Media and its Image', Review of International Political Economy 11(2): 289-310.

Clayman, S.E. (1991) 'News Interview Openings: Aspects of Sequential Organization', in P. Scannell (ed) Broadcast Talk, pp. 48-75. London; Newbury Park: Sage Publications.

Djonov, E. (2005) 'Analysing the Organisation of Information in Websites: From Hypermedia Design to Systemic Functional Hypermedia Discourse Analysis', PhD Thesis, University of New South Wales.

Ellsworth, E. (1997) Teaching Positions: Difference, Pedagogy and the Power of Address. New York: Teachers College Press.

Fairclough, N. (1995) Media Discourse. London; New York: E. Arnold.

Galtung, J. and Ruge, M.H. (1965) 'The Structure of Foreign News,' Journal of Peace Research 2(1): 64-91.

Haddington, P. (2006) 'Identity and Stance Taking in News Interviews: A Case Study', in I. Lassen, J. Strunck and T. Vestergaard (eds) Mediating Ideology in Text and Image: Ten Critical Studies, pp. 69-95.Philadelphia, PA: J. Benjamins.

Halliday, M.A.K. (1994 [1985]) An Introduction to Functional Grammar. Second Edition, London: Edward Arnold. 
Iedema, R. (2003) 'Multimodality, Resemiotization: Extending the Analysis of Discourse as Multi-Semiotic Practice', Visual Communication 2(1): 9-57.

Iedema, R., Feez, S., and White, P.R.R. (1994) Media Literacy. Sydney, Disadvantaged Schools Program, NSW Department of School Education Available online at http://www.grammatics.com/appraisal/MediaLit-Comment.pdf

Knox, J. S. (2009) 'Punctuating the Home Page: Image as Language in an Online Newspaper', Discourse and Communication, 3(2): 145-172.

Kress, G., and van Leeuwen, T. (1998) 'Front Pages: (The Critical) Analysis of Newspaper Layout', in A. Bell and P. Garrett (eds) Approaches To Media Discourse, pp. 186-219. Oxford; Malden, Mass.: Blackwell.

Kress, G., and van Leeuwen, T. (2001) Multimodal Discourse: The Modes and Media of Contemporary Communication. London: Arnold.

Lemke, J.L. (2002) 'Travels in Hypermodality'. Visual Communication 1(3): 299-325.

Machin, D. and Niblock, S. (2006) News Production: Theory and Practice. Abingdon, [England], New York: Routledge.

Masterman, L. (1985) Teaching the Media. London: Comedia.

Montgomery, M. (2007) The Discourse of Broadcast News: A Linguistic Approach. New York: Routledge.

Scollon, R. (1998) Mediated Discourse as Social Interaction: A Study Of News Discourse. London, New York: Longman.

Thornborrow, J. (2001) 'Authenticating Talk: Building Public Identities in Audience Participation Broadcasting', Discourse Studies 3(4): 459-479.

van Dijk, T. A. (1988a) News as Discourse. Hillsdale, New Jersey: Lawrence Erlbaum Associates.

van Dijk, T. A. (1988b) News Analysis: Case Studies of International and National News in the Press. Hillsdale, New Jersey: Lawrence Erlbaum. 
van Leeuwen, T. (1996) 'The Representation of Social Actors', in C.R. Caldas-Coulthard and M. Coulthard (eds) Texts and Practices - Readings in Critical Discourse Analysis, pp. 32-70. London; New York: Routledge.

van Leeuwen, T. (2001). 'Semiotics and Iconography', in T. van Leeuwen and C. Jewitt (eds) Handbook of Visual Analysis, pp. 92-118. London; Thousand Oaks; New Delhi: Sage Publications.

van Leeuwen, T. (2008). Discourse and Practice: New Tools for Critical Discourse Analysis. New York: Oxford University Press.

White, P. R. R. (1997) 'Death, Disruption and the Moral Order: The Narrative Impulse in Mass-'Hard News' Reporting', in F. Christie and J.R. Martin (eds) Genre and Institutions: Social Processes in the Workplace and School, pp. 101-133. New York: Cassell.

News Events:

Bloomberg.com (2008). Bear Stearns Fund Prosecutors Reveal 'Lot of Evidence' of Fraud. Retrieved 20 June 2008, from http://www.bloomberg.com/apps/news?pid=email_en\&refer=home\&sid=aA9pBzndci6I Bloomberg.com (2008). Former Bear Stearns Fund Managers Indicted for Fraud. Retrieved 20 June 2008, [flash pop-up video; no url provided]

CNBC.com (2008). Bear Stearns Indictment. Retrieved 20 June 2008, from http://www.cnbc.com/id/15840232?video=774102483

CNBC.com (2008). Bear Stearns Managers Indicted Over Fund's Collapse. Retrieved 20 June 2008, from http://www.cnbc.com/id/25260431/from/ET/

CNBC.com (2008). Wall Street Witch Hunt. Retrieved 20 June 2008, from http://www.cnbc.com/id/15840232?video=774046361

FOXBusiness.com (2008). Details of the Bear Stearns Hedge Funds Indictments. Retrieved 20 June 2008, from http://emac.blogs.foxbusiness.com/2008/06/19/details-on-the-bearstearns-hedge-fund-indictments/ 
FOXBusiness.com (2008). Two Caged Bears. Retrieved 20 June 2008, from http://www.foxbusiness.com/video/index.html?playerId=videolandingpage\&streamingF ormat $=$ FLASH\&referralObject $=1589853 \&$ referralPlaylistId $=1292 \mathrm{~d} 14 \mathrm{~d} 0 \mathrm{e} 3 \mathrm{afdcf0b} 3150$ 0afefb92724c08f046\&maven_referrer=staf

FOXBusiness.com (2008). Two Ex-Bear Stearns Fund Managers Indicted. Retrieved 20 June 2008, from http://www.foxbusiness.com/story/markets/industries/finance/ex-bearstearns-fund-managers-indicted/

Reuters.com (2008). Ex-Bear Fund Managers Arrested. Retrieved 20 June 2008, from http://www.reuters.com/news/video/videoStory?videoId=84898

Reuters.com (2008). Former Bear Stearns Hedge Fund Managers Indicted. Retrieved 20 June 2008, from http://www.reuters.com/article/email/idUSN1935076220080619 